\title{
Clinical observations associated with proven and unproven cases in the ESCRS study of prophylaxis of postoperative endophthalmitis after cataract surgery
}

Peter Barry, FRCS, Susanne Gardner, DPharm, David Seal, MD, George Gettinby, DPhil, Fiona Lees, MSc, Magnus Peterson, MSc, Crawford Revie, PhD, for the ESCRS Endophthalmitis Study Group

PURPOSE: To describe cases of postoperative endophthalmitis in the European Society of Cataract \& Refractive Surgeons (ESCRS) study of the prophylaxis of endophthalmitis, compare characteristics of unproven cases and cases proven by culture or polymerase chain reaction, and compare the characteristics with those in other reported series.

SETTING: Twenty-four ophthalmology units in Austria, Belgium, Germany, Italy, Poland, Portugal, Spain, Turkey, and the United Kingdom.

METHODS: Univariable and multivariable logistic regression models were used to analyze data for statistical association of signs and symptoms in cases with proven or unproven endophthalmitis. Specific data describing characteristics of the cases were compared between the 2 types of cases.

RESULTS: Data from 29 endophthalmitis cases were analyzed. Swollen lids and pain were statistically associated with proven cases of endophthalmitis on univariable regression analysis. Multivariable analysis indicated that swollen lids and an opaque vitreous were associated with proven cases. Five cases of endophthalmitis occurred in the cefuroxime-treated groups. No case of streptococcal infection occurred in the cefuroxime-treated groups. However, cases of infection due to streptococci showed striking differences in visual acuity and were associated with earlier onset. Characteristics in the 29 cases parallel results in previous studies, such as the Endophthalmitis Vitrectomy Study, although the addition of a control group in the ESCRS study elicited additional findings.

CONCLUSION: Swollen lids, pain, and an opaque vitreous were statistically associated with proven endophthalmitis cases in the ESCRS study.

The results and rationale for the European Society of Cataract \& Refractive Surgeons (ESCRS) study of the prophylaxis of endophthalmitis after cataract surgery have been presented, ${ }^{1-3}$ as has a description of the microbiologic and molecular methods used. ${ }^{4}$ Intracameral injection of $1 \mathrm{mg}$ cefuroxime in the 2 cefuroxime-treated groups resulted in a nearly 5-fold reduction in the rates of postoperative endophthalmitis over rates in study groups that did not receive the intracameral injection. ${ }^{1}$ We present characteristics of each case of endophthalmitis in the study and compare the signs and symptoms in proven cases and unproven cases.

\section{PATIENTS AND METHODS}

Data from the cases of endophthalmitis in the ESCRS study of the prophylaxis of endophthalmitis after cataract surgery were reviewed for comparison of clinical characteristics. The clinical signs and symptoms in cases of proven en dophthalmitis were compared with those in unproven cases. The data were compiled by time to diagnosis, visual acuity, microbiology results, and additional factors, in cluding patient demographics, incision site, intraocular lens (IOL) material, surgeon experience, and surgical complications.

Proven endophthalmitis was defined as any case present ing with pain or loss of vision thought to be due to infection and in which infection was proven by Gram stain, culture, or polymerase chain reaction. Unproven or presumed 
endophthalmitis was determined to be present when no test yielded a positive result.

Data in the results presented here refer to the randomiza tion protocol used in the ESCRS study. ${ }^{1}$ Group A, a control group, received an intensive placebo drop regimen perioper atively ${ }^{1}$; Group $C$ received the active intensive perioperative antibiotic drop regimen (levofloxacin $0.5 \%$ ). In Group B, an intracameral injection of cefuroxime $1 \mathrm{mg}$ was added to the regimen in Group A; in Group D, intracameral cefuroxime $1 \mathrm{mg}$ was added to the regimen in Group C. All groups were prescribed a standard postoperative antibiotic drop regimen comprising topical levofloxacin 0.5\%, 1 drop 4 times daily, for at least 1 week to prevent wound infection. In all, approx imately one half (8108) of the intent to treat patients received an intracameral injection of cefuroxime $1 \mathrm{mg}$ and one half (8103) did not.

The endpoint of the study was the diagnosis of endoph thalmitis. The subsequent management of individual patients was at the discretion of the responsible surgeon. No aspects of subsequent treatment were randomized, and recording of the final visual outcome did not occur at a fixed time point after diagnosis. Therefore, postoperative visual acuities could not be subjected to statistical testing.

\section{Statistical Analysis}

Logistic regression analysis was performed to determine whether any sign or symptom recorded for each patient when he or she presented with endophthalmitis was more frequently associated with proven or unproven cases. Each factor was screened individually using univariable binary logistic regression. All factors with a likelihood ratio test $P$ value of 0.20 or less were made available for final multivari able logistic regression analyses. The likelihood ratio test sta tistical significance of each factor is reported with its odds ratio (OR) and associated $95 \%$ confidence interval (CI).

\section{RESULTS}

Of the 29 cases of endophthalmitis in the ESCRS study, 20 were proven and 9 were unproven. The median time to presentation with signs and symptoms was 4.5 days ( 4.0 days if the 1 late-presenting case at 132 days is discounted) in proven cases and 9.0 days in

From Royal Victoria Eye and Ear Hospital (Barry), Dublin, Ireland; Applied Vision Research Centre (Seal), City University, London, United Kingdom; Department of Computer and Information Sciences, Department of Mathematics and Statistics (Gettinby, Lees, Peterson, Revie), University of Strathclyde, Glasgow, Scotland; Atlanta, Georgia, USA, (Gardner).

No author has a financial or proprietary interest in any material or method mentioned.

Corresponding author: Peter Barry, FRCS, Royal Victoria Eye Ear Hospital, The Eye Clinic, 33 Herbert Avenue, Merrion Road, Dublin 4, Ireland. E-mail: peterbarryfrcs@eircom.net.
Table 1. Time to onset of signs and symptoms in 29 cases of endophthalmitis.

\begin{tabular}{lccc}
\hline & \multicolumn{3}{c}{ Cases } \\
\cline { 2 - 4 } Days to Onset & Total & Proven & Unproven \\
\hline 13 & 9 & 8 & 1 \\
47 & 9 & 7 & 2 \\
814 & 7 & 3 & 4 \\
$>14$ & 4 & 2 & 2 \\
\hline
\end{tabular}

unproven cases; the median time overall was 5 days. Table 1 shows the distribution of cases grouped by time to onset; a greater proportion of proven cases occurred within the first 7 days postoperatively.

Table 2 shows the visual acuity and the signs and symptoms on presentation postoperatively. Table 3 shows the signs and symptoms by case and the results of univariable logistic regression analysis, which indicated that swollen lids and pain were the only sign or symptom significantly associated with proven cases.

After multivariable logistic regression modeling, swollen lids $(P \quad .04$; OR 18.29 ; 95\% CI, 1.07 311.42) and an opaque vitreous $(P \quad .05$; OR 13.70; 95\% CI, 1.06-177.16) were found to be significantly associated with the proven cases of endophthalmitis. A review of cases that did not have pain, swollen lids, or opaque vitreous, performed to determine whether there were common factors, showed that 1 unmixed case of infection due to Propionibacterium acnes was not associated with pain or swollen lids but was associated with an opaque vitreous. All 8 cases caused by streptococcal infection were associated with pain, hypopyon, and chemotic conjunctiva and with clear corneal incisions (Table 4). No commonality of microbial species with other factors was evident among cases, with further analysis impractical due to the small numbers involved.

Although postoperative visual acuities striking were not statistically tested, there was a difference in visual outcomes between cases of streptococcal and cases of staphylococcal infections, with the outcomes being far worse in streptococcal cases. The final visual acuity range in staphylococcal infections (11 cases, excluding 1 mixed case) was between 20/20 and 20/ 80 , with no patient being legally blind (ie, $20 / 200$ or worse); 3 of these cases received an intracameral cefuroxime injection. Conversely, the final visual acuity range in streptococcal infections ( 8 cases) was between 20/20 and no light perception; 5 of these patients were legally blind, all due to streptococci, and none of the 5 received intracameral cefuroxime (Table 4). All 8 cases with streptococcal infection were in the groups that did not receive intracameral cefuroxime. 
Table 4 shows the microorganisms isolated in the 20 cases of proven endophthalmitis, ordered by time to onset of signs and symptoms as well as the data from all 29 cases by treatment group, age, and sex. It also shows the distribution of risk factors identified as significant in the overall study results. These include site of incision, IOL optic material, surgeon experience, and presence of surgical complications.

Of the 29 endophthalmitis cases, 8 proven cases and 1 unproven case presented within 1 to 3 days postoperatively; all 8 cases were in Group A or Group C, which did not receive an intracameral injection of cefuroxime (Table 4 ). There was no case of early-onset ( 1 to 3 days) endophthalmitis in the 2 groups that received an intracameral cefuroxime injection. The early-onset cases included 6 isolates of streptococcal species and 2 isolates of Staphylococcus epidermidis and were generally associated with rapid and severe onset of symptoms.

Of the endophthalmitis cases presenting from 4 to 7 days, 7 were proven and 2 were unproven. Five of the 7 proven cases occurred in the groups that did not receive intracameral cefuroxime and 2 cases, in the groups that received intracameral cefuroxime.

The 7 cases with an onset of 8 to 14 days included 3 proven and 4 unproven cases. Of the proven cases, 1 occurred in a cefuroxime-treated group (Group B); in this case, $S$ epidermidis was isolated and poor wound healing was reported. Of the unproven cases, 1 was in a cefuroxime-treated group and was associated with an operative complication.

The 2 late-onset proven cases ( $>14$ days) occurred in control Group A, which did not receive cefuroxime, and included 1 case of $S$ epidermidis and 1 of Propionibacterium species. Two late-onset unproven cases also occurred, both in Group A.

\section{DISCUSSION}

We describe the signs, symptoms, and characteristics of endophthalmitis cases in the largest series of patients evaluated for evidence-based prophylaxis of endophthalmitis after cataract surgery in a randomized clinical trial. Our data from the 16211 intent-to-treat patients were unique in the inclusion of a control group to permit statistical evaluation of the specific intervention; that is, intracameral injection of $1 \mathrm{mg}$ cefuroxime at the close of cataract surgery.

The report of the Endophthalmitis Vitrectomy Study (EVS), which was conducted from 1990 to 1994, describes a comparable series of patients with postoperative endophthalmitis. ${ }^{5}$ Many characteristics in the EVS study align with findings in the ESCRS study (Table 5). There were more patients in the EVS study because all were presumed cases of endophthalmitis referred for treatment within a study protocol; however, prophylactic perioperative treatments varied, and recruitment was limited to 6 weeks postoperatively.

The median time to diagnosis in the United Statesbased EVS study and the European-based ESCRS study was similar (6 days and 5 days, respectively); the early-presenting patients in the control group are the likely reason for the shorter time in the ESCRS study. The majority of patients in both studies presented within 7 days after cataract surgery. In another series that comprised culture-proven endophthalmitis cases (73 eyes) only, ${ }^{6}$ the mean time to presentation overall was 13 days (median 9 days); however, for the $42 \%$ of patients who presented within 7 days after cataract surgery, the mean time to presentation was 5 days. The somewhat longer time to presentation overall in that study was associated with the use of the clear corneal incision, whereas the EVS was associated with the scleral incision technique. In the ESCRS study, which used both surgical methods, $75 \%$ of proven endophthalmitis cases presented within 7 days.

The frequency of patients presenting with pain, swollen lids, and hypopyon is also comparable, although the EVS study did not analyze differences in signs and symptoms between proven cases and unproven cases. In the ESCRS study, hypopyon was present in $80 \%$ of proven cases and $56 \%$ of unproven cases, resulting in an overall incidence of $72 \%$.

The percentage of culture-proven cases (69\%) was identical in both studies and aligned with the $62 \%$ culture-positive cases described in an Asian report. ${ }^{7}$ The frequency of total gram-positive microorganisms was almost identical $(63 \%$ versus $62 \%)$ in the 2 studies, although streptococci were encountered more frequently in the ESCRS study. Streptococcal endophthalmitis resulted in earlier onset and notably worse outcomes than infection by staphylococcal species, a trend also reflected in EVS results and elsewhere. $^{8-10}$ In a series by Lalwani et al., ${ }^{6}$ Streptococcus species were identified in $8.2 \%$ of isolates overall, with most $(83.3 \%)$ occurring in the early-presenting group. In the ESCRS study, $75.0 \%(6 / 8)$ of streptococcal cases presented within 3 days and $100 \%$ within 7 days. None of the eyes in the ESCRS study with the worst visual outcomes after streptococcal infection received intracameral cefuroxime. This indicates that the cefuroxime injection was an important factor in protecting patients against the development of postoperative streptococcal endophthalmitis with its associated destructive sequelae, which often result in a poor visual outcome. These cases of streptococcal infection reemphasize the importance of this pathogen in the etiology of postoperative endophthalmitis and suggest that proposed regimens for prophylaxis of endophthalmitis ensure microbiologic efficacy against this class of microbes. 


\begin{tabular}{|c|c|c|c|c|c|c|}
\hline \multirow[b]{2}{*}{$\begin{array}{l}\text { Case } \\
\text { Type/\# }\end{array}$} & \multirow[b]{2}{*}{ VA } & \multicolumn{5}{|c|}{ Sign or Symptom } \\
\hline & & $\begin{array}{c}\text { Corneal } \\
\text { Edema }\end{array}$ & Hypopyon & Opaque Vit & $\begin{array}{c}\text { Vit } \\
\text { Condensation }\end{array}$ & $\begin{array}{l}\text { Chemotic } \\
\text { Conj }\end{array}$ \\
\hline \multicolumn{7}{|l|}{ Proven } \\
\hline 28 & $<20 / 200$ & $\boldsymbol{V}$ & レ & $\boldsymbol{V}$ & $\mathrm{N}$ & $\boldsymbol{V}$ \\
\hline 10 & $20 / 200$ & $\boldsymbol{V}$ & $\boldsymbol{\nu}$ & レ & - & レ \\
\hline 22 & $<20 / 200$ & レ & レ & レ & レ & レ \\
\hline 21 & $20 / 40$ & レ & $レ$ & - & - & レ \\
\hline 27 & $<20 / 200$ & $\nu$ & 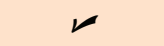 & $\boldsymbol{v}$ & $\swarrow$ & $\boldsymbol{V}$ \\
\hline 9 & $<20 / 200$ & - & レ & $\boldsymbol{V}$ & $\boldsymbol{V}$ & レ \\
\hline 14 & $<20 / 200$ & $\boldsymbol{V}$ & レ & r & レ & レ \\
\hline 3 & $20 / 40$ & - & レ & - & $\mathrm{N}$ & レ \\
\hline 17 & $<20 / 200$ & $\nu$ & $\nu$ & $\boldsymbol{v}$ & $\mathrm{N}$ & - \\
\hline $4^{*}$ & $<20 / 200$ & $\nu$ & - & - & - & 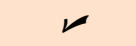 \\
\hline $12^{*}$ & $<20 / 200$ & レ & $\boldsymbol{}$ & $\boldsymbol{v}$ & $\mathrm{N}$ & - \\
\hline 6 & $20 / 60$ & $\boldsymbol{r}$ & レ & r & レ & レ \\
\hline 2 & $<20 / 200$ & レ & レ & $\boldsymbol{v}$ & - & $\boldsymbol{\nu}$ \\
\hline 25 & $<20 / 200$ & $\nu$ & $\nu$ & $\nu$ & $\nu$ & - \\
\hline 18 & $<20 / 200$ & $v$ & $\boldsymbol{\nu}$ & $\mathrm{N}$ & $\mathrm{N}$ & - \\
\hline 5 & $20 / 200$ & 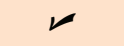 & - & $\mathrm{N}$ & - & $r$ \\
\hline 24 & $20 / 200$ & $\boldsymbol{v}$ & $\boldsymbol{r}$ & $\nu$ & $\nu$ & $\nu$ \\
\hline $8^{*}$ & $<20 / 200$ & $\nu$ & $\nu$ & - & - & - \\
\hline 20 & $20 / 120$ & $\nu$ & - & - & $\nu$ & - \\
\hline 29 & $20 / 80$ & - & - & $v$ & 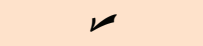 & - \\
\hline Nonproven & & & & & - & - \\
\hline 16 & $20 / 80$ & $v$ & $\nu$ & - & - & $\boldsymbol{v}$ \\
\hline $15^{*}$ & $20 / 200$ & $\nu$ & - & - & $\nu$ & $\nu$ \\
\hline 19 & $20 / 200$ & $v$ & - & - & レ & - \\
\hline $1^{*}$ & $20 / 200$ & 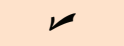 & $\nu$ & - & $\nu$ & $r$ \\
\hline 11 & $<20 / 200$ & - & - & $\nu$ & - & - \\
\hline 13 & $<20 / 200$ & 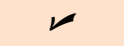 & $\boldsymbol{\nu}$ & - & - & - \\
\hline 26 & $<20 / 200$ & - & $\nu$ & $\nu$ & - & - \\
\hline 7 & $<20 / 200$ & $r$ & $\nu$ & $\mathrm{N}$ & $\mathrm{N}$ & - \\
\hline 23 & $<20 / 200$ & $v$ & - & $\mathrm{N}$ & 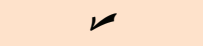 & - \\
\hline
\end{tabular}

Five cases of endophthalmitis (3 proven, 2 unproven) occurred in the ESCRS study groups that received an intracameral cefuroxime injection. One unproven case involved an intraoperative complication. In another series, ${ }^{11}$ approximately one half of the endophthalmitis cases were also associated with intraoperative complications. One proven case in a cefuroxime-treated group, which presented 13 days postoperatively, was associated with poor wound apposition. This occurred in a patient whose occupation was hospital based, raising the possibility that a postoperative nosocomial infection with a less susceptible strain of $S$ epidermidis occurred at the wound site. The isolate was termed resistant to cefuroxime by previous definitions. ${ }^{4}$ Another isolate in the cefuroxime-treated groups was identified as Staphylococcus warneri in a patient presenting 4 days after surgery with visual acuity worse than 6/60, swollen lids, and corneal edema, but no hypopyon or vitreous condensation. This isolate was lost to sensitivity testing for cefuroxime, although culture results indicated susceptibility to several antibiotics, including methicillin, but resistance to penicillin and gentamicin. Ocular isolates of $S$ warneri are described in the literature, identified from corneal/external eye infections in patients with chronic blepharitis, purulent conjunctivitis, and suppurative keratitis ${ }^{12}$ and in hospitals, neonatal units, and food. ${ }^{13-15}$ The third isolate in cefuroxime-treated groups was $S$ epidermidis, determined to be sensitive to cefuroxime. 


\begin{tabular}{|c|c|c|c|c|c|c|c|c|}
\hline \multicolumn{9}{|c|}{ Sign or Symptom } \\
\hline $\begin{array}{l}\text { Pupil } \\
\text { Memb }\end{array}$ & $\begin{array}{l}\text { Swollen } \\
\text { Lid }\end{array}$ & $\begin{array}{l}\text { View of } \\
\text { Fundus }\end{array}$ & $\begin{array}{c}\text { View } \\
\text { of Retinal } \\
\text { Vessels }\end{array}$ & $\begin{array}{l}\text { Loss } \\
\text { of Red } \\
\text { Reflex }\end{array}$ & $\begin{array}{c}\text { Blurred } \\
\text { Vision }\end{array}$ & $\begin{array}{l}\text { Loss } \\
\text { of Vision }\end{array}$ & Pain & Other \\
\hline- & $\nu$ & - & - & $r$ & $\mathrm{~N}$ & $\boldsymbol{r}$ & $\nu$ & - \\
\hline $\boldsymbol{\nu}$ & $\nu$ & $\boldsymbol{\nu}$ & $\nu$ & $\boldsymbol{\nu}$ & & $\boldsymbol{\nu}$ & $\boldsymbol{\nu}$ & $\boldsymbol{\nu}$ \\
\hline- & - & - & - & $\nu$ & $\boldsymbol{\nu}$ & $\nu$ & $\nu$ & - \\
\hline$r$ & $r$ & $r$ & $r$ & - & $\boldsymbol{r}$ & $\nu$ & $\nu$ & - \\
\hline- & $r$ & - & - & - & $\boldsymbol{r}$ & $\boldsymbol{\nu}$ & $\nu$ & - \\
\hline $\boldsymbol{r}$ & $\boldsymbol{r}$ & - & - & - & $r$ & $\boldsymbol{\nu}$ & $\nu$ & - \\
\hline- & $\boldsymbol{\nu}$ & - & - & - & $\boldsymbol{\nu}$ & $\boldsymbol{\nu}$ & $\boldsymbol{\nu}$ & - \\
\hline$\nu$ & $\mathrm{N}$ & $\nu$ & $\nu$ & - & - & - & $\nu$ & $\boldsymbol{\nu}$ \\
\hline- & - & - & - & - & $\boldsymbol{\nu}$ & $\boldsymbol{\nu}$ & $\boldsymbol{\nu}$ & - \\
\hline$\nu$ & $\nu$ & $\nu$ & $\nu$ & - & $\nu$ & $\boldsymbol{\nu}$ & $\nu$ & - \\
\hline $\boldsymbol{\nu}$ & $\boldsymbol{r}$ & - & - & $\mathrm{N}$ & $r$ & $r$ & $\nu$ & - \\
\hline$\nu$ & $\nu$ & $\nu$ & $\nu$ & - & $\nu$ & - & $\nu$ & - \\
\hline $\boldsymbol{\nu}$ & $\boldsymbol{\nu}$ & - & - & $\nu$ & $\boldsymbol{\nu}$ & $\boldsymbol{\nu}$ & $\nu$ & - \\
\hline- & - & - & - & $\nu$ & $\nu$ & $\boldsymbol{\nu}$ & $\nu$ & - \\
\hline$\nu$ & - & - & - & $v$ & $v$ & $v$ & $\nu$ & - \\
\hline $\boldsymbol{\nu}$ & $\nu$ & $r$ & - & - & $\nu$ & $\boldsymbol{\nu}$ & $\nu$ & - \\
\hline- & - & - & - & - & $\nu$ & $v$ & $\nu$ & - \\
\hline- & $\boldsymbol{\nu}$ & - & - & - & $\nu$ & $\boldsymbol{r}$ & - & - \\
\hline- & - & $\boldsymbol{\nu}$ & $\boldsymbol{\nu}$ & - & $\boldsymbol{\nu}$ & - & $\boldsymbol{\nu}$ & - \\
\hline$\nu$ & & $\nu$ & $\nu$ & - & $\nu$ & $\nu$ & - & - \\
\hline$\nu$ & - & - & - & - & $\boldsymbol{r}$ & $r$ & - & - \\
\hline- & $\nu$ & $\nu$ & $\nu$ & - & $\nu$ & $\nu$ & $v$ & - \\
\hline$\nu$ & - & $\nu$ & $\nu$ & - & $\nu$ & $\mathrm{N}$ & - & - \\
\hline- & - & $\mathrm{N}$ & $\mathrm{N}$ & $\nu$ & $\nu$ & $\nu$ & $\nu$ & $\nu$ \\
\hline- & - & - & $\nu$ & - & $r$ & $r$ & - & - \\
\hline$\nu$ & - & - & - & - & $\nu$ & $r$ & - & - \\
\hline- & - & - & - & - & $\nu$ & $v$ & - & - \\
\hline $\mathrm{N}$ & - & $\mathrm{N}$ & $\mathrm{N}$ & $\mathrm{N}$ & $\nu$ & $\nu$ & $\nu$ & - \\
\hline- & - & - & - & $r$ & $\nu$ & $r$ & $\nu$ & - \\
\hline
\end{tabular}

Two cases of unproven endophthalmitis occurred in the cefuroxime-treated groups; an intraoperative complication was associated with 1 of the cases. Intraoperative complications were also associated with culture-negative cases in another series ${ }^{16}$ in which endophthalmitis occurred after a variety of surgical procedures.

In the intent-to-treat patient population that received intracameral cefuroxime (Group B and Group D), the rate of total endophthalmitis was $0.062 \%$. The rate in patients who did not receive cefuroxime (Group A and Group C) was approximately 5 times higher $(0.296 \%)$. The baseline rates in ESCRS study groups not receiving cefuroxime may be compared with presumed postoperative endophthalmitis rates $\left(0.215 \%,{ }^{17} 0.265 \%,{ }^{18} 0.286 \%\right.$ and at times $\left.0.330 \%{ }^{19}\right)$ in studies that included patient populations in referral centers or older patients or with rates associated with changing trends in surgical technique. Despite changes in surgical techniques and an increasingly elderly population, the rate of endophthalmitis after cataract surgery remained near $0.2 \%$ in a Western Australia study that spanned almost 2 decades. ${ }^{20}$ These series presumably incorporated some form of perioperative prophylaxis and did not include control groups. A more contemporary analysis ${ }^{21}$ found a $0.35 \%$ rate of postoperative endophthalmitis in a group of patients who did not receive intracameral cefuroxime. This is an especially relevant comparison to the ESCRS findings because topical antibiotic 


\begin{tabular}{|c|c|c|c|c|c|}
\hline \multirow[b]{2}{*}{ Parameter } & \multicolumn{2}{|c|}{ Percentage $^{\dagger}$} & \multicolumn{3}{|c|}{ Univariable Logistic Regression } \\
\hline & Proven Cases & Unproven Cases & $P$ Value & OR & $95 \% \mathrm{CI}$ \\
\hline \multicolumn{6}{|l|}{ Sign } \\
\hline VA $20 / 200$ or worse & 75 & 89 & .41 & 0.38 & 0.043 .79 \\
\hline Corneal edema & 85 & 78 & .64 & 1.62 & 0.2211 .89 \\
\hline Hypopyon & 80 & 56 & .18 & 3.20 & 0.5817 .72 \\
\hline Vitreous opaque & 72 & 29 & .06 & 6.50 & 0.9445 .11 \\
\hline Vitreous condensation & 60 & 50 & .65 & 1.50 & 0.278 .45 \\
\hline Chemotic conjunctiva & 65 & 33 & .12 & 3.71 & 0.7019 .59 \\
\hline Pupillary membrane & 55 & 38 & .41 & 2.04 & 0.3810 .94 \\
\hline Swollen lids & 63 & 11 & .02 & 13.71 & 1.41133 .85 \\
\hline View of fundus & 40 & 29 & .59 & 1.67 & 0.2610 .79 \\
\hline View of retinal vessels & 35 & 43 & .71 & 0.72 & 0.124 .16 \\
\hline Loss of red reflex & 32 & 25 & .73 & 1.38 & 0.218 .98 \\
\hline \multicolumn{6}{|l|}{ Symptom } \\
\hline Blurring of vision* & 89 & 100 & - & - & - \\
\hline Loss of vision* & 85 & 100 & - & - & - \\
\hline Pain & 90 & 56 & .05 & 7.20 & 1.0151 .39 \\
\hline Other & 10 & 11 & .93 & 0.89 & 0.0711 .28 \\
\hline
\end{tabular}

ointment or drops were not routinely used at those centers.

Such reports underscore the value of the ESCRS study results in answering the call for randomized trials to contribute statistically valid data for strategies to reduce endophthalmitis rates as patient numbers increase worldwide. ${ }^{17}$ In particular, because reported rates of anterior chamber contamination during cataract surgery are extraordinarily high $\left(20 \%\right.$ to $24 \%,{ }^{22}$ $29 \%,{ }^{23} 43 \%{ }^{24}$ ), it should not be surprising to find baseline endophthalmitis rates in ESCRS control groups that reflect the higher range of reported rates. The lower endophthalmitis rates in cefuroxime-treated groups parallel those in other series in the literature; however, without predefined study protocols to address the significance of specific interventions, assumptions outside the ESCRS study remain speculative and clouded by the many factors at play in various surgical settings.

To date, intracameral cefuroxime remains the only prophylactic intervention proven to reduce rates of endophthalmitis after cataract surgery. Although fourthgeneration fluoroquinolones have been promoted as a potential substitute for intracameral cefuroxime, recent reports describing steadily increasing resistance of endophthalmitis isolates to fourth-generation fluoroquinolones ring a cautionary note. From 1990 to 2004, in 111 ocular endophthalmitis isolates of coagulase-negative Staphylococcus (CNS), $67.6 \%$ being $S$ epidermidis, the percentage of strains sensitive to moxifloxacin declined significantly from 96.6\% (1990 to $1994)$ to $65.4 \%$ (2000 to 2004) $(P \quad .03)$, a $32.2 \%$ decline over a relatively short period. ${ }^{25}$

A significant increase in the prevalence of resistant isolates was also documented for moxifloxacin over this time period $(P \quad$.007). The minimum inhibitory concentration required to inhibit the growth of $90 \%$ of organisms for moxifloxacin increased by a factor of 266 , rising from $0.12 \mu \mathrm{g} / \mathrm{mL}$ (93.2\% of isolates) during 1990 to 1994 , to $4.00 \mu \mathrm{g} / \mathrm{mL}$ ( $100 \%$ of isolates) during 1995 to 1999 , and to $32.00 \mu \mathrm{g} / \mathrm{mL}$ ( $100 \%$ of isolates) during 2000 to 2004 . Overall, only $72.1 \%$ of the 111 CNS isolates recovered from patients with clinical endophthalmitis were considered sensitive to moxifloxa$\operatorname{cin}(\leq 0.5 \mu \mathrm{g} / \mathrm{mL}){ }^{25}$

In the ESCRS study, 2 to 3 of the $5 S$ epidermidis isolates tested showed reduced susceptibility to moxifloxacin. ${ }^{4}$ This trend, together with reports describing postoperative endophthalmitis despite perioperative and postoperative use of fourth-generation fluoroquinolone drops, ${ }^{26}$ the potentially unresolved questions of safe dosage ${ }^{27}$ and cautionary statements that eyedrops such as moxifloxacin should not be injected directly into the eye (Alcon Laboratories, Vigamox product insert), suggest that further large-scale randomized trials are required to validate any substitutions of cefuroxime for intracameral injection at this time. 


\begin{tabular}{|c|c|c|c|c|c|c|c|c|c|}
\hline $\begin{array}{l}\text { Case } \\
\text { Type/\# }\end{array}$ & $\begin{array}{l}\text { Days to } \\
\text { Onset }\end{array}$ & Organism & $\begin{array}{l}\text { Tx } \\
\text { Group }\end{array}$ & $\begin{array}{l}\text { Sex/Age } \\
\text { (Y) }\end{array}$ & Incision Site & $\begin{array}{l}\text { IOL Optic } \\
\text { Material }\end{array}$ & $\begin{array}{c}\text { Surgeon } \\
\text { Experience } \\
\text { (\# of Surgeries) }\end{array}$ & $\begin{array}{l}\text { Surgical } \\
\text { Complications }\end{array}$ & $\begin{array}{c}\text { Visual } \\
\text { Outcome }^{\dagger}\end{array}$ \\
\hline \multicolumn{10}{|l|}{ Proven } \\
\hline 28 & 1 & Streptococcus salivarius & C & $\mathrm{M} / 70$ & Clear corneal & Silicone & $>500$ & No & $20 / 60$ \\
\hline 10 & 2 & Streptococcus pneumoniae & A & $\mathrm{M} / 79$ & Clear corneal & Silicone & $>500$ & No & $<20 / 200$ \\
\hline 22 & 2 & Streptococcus pneumoniae & A & $\mathrm{M} / 75$ & Clear corneal & Silicone & $>500$ & No & $<20 / 200$ \\
\hline 21 & 2 & Streptococcus salivarius & A & $\mathrm{F} / 69$ & Clear corneal & Acrylic & $>500$ & No & $<20 / 200$ \\
\hline 27 & 2 & Streptococcus sanguis & C & $\mathrm{M} / 78$ & Clear corneal & Acrylic & $>500$ & No & $<20 / 200$ \\
\hline 9 & 3 & Staphylococcus epidermidis & $\mathrm{C}$ & $\mathrm{F} / 81$ & Scleral tunnel & Silicone & $<100$ & No & $20 / 25$ \\
\hline 14 & 3 & Staphylococcus epidermidis & A & $\mathrm{M} / 62$ & Clear corneal & Acrylic & $>500$ & Yes & $20 / 25$ \\
\hline 3 & 3 & Streptococcus oralis & C & $\mathrm{F} / 66$ & Clear corneal & Acrylic & $>500$ & No & $20 / 200$ \\
\hline 17 & 4 & Staphylococcus epidermidis & A & $\mathrm{F} / 79$ & Clear corneal & Silicone & $>500$ & No & $20 / 30$ \\
\hline $4^{*}$ & 4 & Staphylococcus warneri & $\mathrm{D}$ & $\mathrm{F} / 63$ & Clear corneal & Acrylic & 100500 & No & $20 / 80$ \\
\hline $12^{*}$ & 5 & Staphylococcus epidermidis & B & $\mathrm{M} / 81$ & Clear corneal & Acrylic & $>500$ & No & $20 / 80$ \\
\hline 6 & 5 & $\begin{array}{c}\text { Staphylococcus epidermidis/ } \\
\text { Streptococcus mitis }\end{array}$ & A & $\mathrm{M} / 67$ & Clear corneal & Silicone & $>500$ & No & $20 / 20$ \\
\hline 2 & 5 & Streptococcus suis & A & $\mathrm{M} / 68$ & Clear corneal & Acrylic & $>500$ & Yes & $20 / 30$ \\
\hline 25 & 7 & Staphylococcus epidermidis & $\mathrm{C}$ & $\mathrm{M} / 91$ & Clear corneal & Acrylic & $>500$ & No & $20 / 25$ \\
\hline 18 & 7 & $\begin{array}{l}\text { Staphylococcus hominis } \\
\text { or haemolyticus }\end{array}$ & C & $\mathrm{M} / 83$ & Clear corneal & Silicone & $>500$ & No & $20 / 40$ \\
\hline 5 & 8 & $\begin{array}{l}\text { Staphylococcus aureus/ } \\
\text { Propionibacterium acnes }\end{array}$ & A & $\mathrm{M} / 71$ & Clear corneal & Acrylic & $>500$ & No & $20 / 30$ \\
\hline 24 & 10 & Staphylococcus aureus & C & $\mathrm{M} / 69$ & Clear corneal & Acrylic & $>500$ & No & $20 / 60$ \\
\hline $8^{*}$ & 13 & Staphylococcus epidermidis & B & $\mathrm{M} / 73$ & Clear corneal & Silicone & $>500$ & No & $20 / 25$ \\
\hline 20 & 16 & Staphylococcus epidermidis & A & $\mathrm{F} / 69$ & Clear corneal & Silicone & $>500$ & No & $20 / 20$ \\
\hline 29 & 132 & Propionibacterium acnes & $\mathrm{A}$ & $\mathrm{F} / 68$ & Clear corneal & Silicone & $>500$ & No & $20 / 20$ \\
\hline \multicolumn{10}{|c|}{ Nonproven } \\
\hline 16 & 3 & - & $\mathrm{C}$ & $\mathrm{M} / 71$ & Scleral tunnel & Silicone & 100500 & No & $20 / 40$ \\
\hline $15^{*}$ & 4 & - & $\mathrm{D}$ & $\mathrm{F} / 72$ & Clear corneal & Acrylic & $>500$ & No & $20 / 25$ \\
\hline 19 & 4 & - & $\mathrm{C}$ & $\mathrm{F} / 78$ & Clear corneal & Acrylic & $<100$ & No & $20 / 30$ \\
\hline $1^{*}$ & 9 & - & $\mathrm{B}$ & $\mathrm{F} / 82$ & Clear corneal & Silicone & $>500$ & Yes & $20 / 60$ \\
\hline 11 & 9 & - & A & $\mathrm{F} / 74$ & Clear corneal & Silicone & 100500 & Yes & $20 / 25$ \\
\hline 13 & 9 & - & C & $\mathrm{F} / 76$ & Clear corneal & Acrylic & $>500$ & No & $20 / 40$ \\
\hline 26 & 11 & - & A & $\mathrm{F} / 83$ & Clear corneal & Acrylic & $>500$ & No & $20 / 20$ \\
\hline 7 & 15 & - & A & $\mathrm{M} / 76$ & Clear corneal & Acrylic & $>500$ & No & $20 / 30$ \\
\hline 23 & 36 & - & A & $\mathrm{M} / 85$ & Clear corneal & Acrylic & $>500$ & No & $20 / 80$ \\
\hline
\end{tabular}

Formulated and manufactured as an injectable, cefuroxime meets safety standards for drugs intended for injection rather than topical use. The safety of intracameral cefuroxime is supported in large numbers of patients ${ }^{28,29}$ as well as by optical coherence tomography after a $1 \mathrm{mg}$ dose, after which no significant effect on postoperative macular thickness was found. ${ }^{30}$

In conclusion, comparison of the signs and symptoms in cases of proven and unproven postoperative endophthalmitis in the ESCRS study showed that swollen lids, pain, and opaque vitreous were statistically associated with the proven cases. Many characteristics of the ESCRS study parallel those of the EVS study and reports from other regions. Five endophthalmitis cases
(3 proven, 2 unproven) occurred in cefuroxime-treated groups; 1 of these was associated with poor wound healing and another, with an intraoperative complication, similar to findings in other reported series. The rates of endophthalmitis in ESCRS study groups parallel those in a spectrum of reports that reflect the variety of surgical settings and patient populations described in the literature worldwide. The ESCRS study groups that received an intracameral injection of cefuroxime had a near 5-fold reduction in postoperative endophthalmitis. Intracameral cefuroxime remains the only prophylactic intervention to date with an evidencebased benefit in the reduction of endophthalmitis after cataract surgery. 
Table 5. Comparison of ESCRS and EVS studies.

\begin{tabular}{|c|c|c|}
\hline \multirow[b]{2}{*}{ Parameter } & \multicolumn{2}{|c|}{ Study } \\
\hline & ESCRS & EVS \\
\hline Number of cases & 29 & 420 \\
\hline Positive cultures* (\%) & 69 & 69 \\
\hline Coagulase negative gm + & 24 & 47 \\
\hline Other gm + & 38 & 16 \\
\hline Total gm + & 62 & 63 \\
\hline $\mathrm{Gm}$ & 0 & 4 \\
\hline Mixed & 7 & 3 \\
\hline Median time to presentation (d) & 5 & 6 \\
\hline \multicolumn{3}{|l|}{ Presentation $(\%)$} \\
\hline Within 3 days & 31 & 24 \\
\hline Within 47 days & 31 & 37 \\
\hline Within 814 days & 24 & 17 \\
\hline Beyond 14 days & 14 & 22 \\
\hline \multicolumn{3}{|l|}{ Sign/symptom (\%) } \\
\hline Hypopyon & 72 & 86 \\
\hline Pain & 79 & 74 \\
\hline Swollen lids & 46.5 & 34.5 \\
\hline
\end{tabular}

\section{REFERENCES}

1. ESCRS Endophthalmitis Study Group. Prophylaxis of postoperative endophthalmitis following cataract surgery: results of the ESCRS multicenter study and identification of risk factors. J Cataract Refract Surg 2007; 33:978 988

2. Barry P, Seal DV, Gettinby G, Lees F, Peterson M, Revie CW. ESCRS study of prophylaxis of postoperative endophthalmitis after cataract surgery; preliminary report of principal results from a European multicenter study; the ESCRS Endophthalmitis Study Group. J Cataract Refract Surg 2006; 32:407 410

3. Seal DV, Barry P, Gettinby G, Lees F, Peterson M, Revie CW, Wilhelmus KR. ESCRS study of prophylaxis of postoperative endophthalmitis after cataract surgery; case for a European multicenter study; the ESCRS Endophthalmitis Study Group. J Cataract Refract Surg 2006; 32:396 406

4. Seal D, Reischl U, Behr A, Ferrer C, Alio J. Koerner, Barry P. Laboratory diagnosis of endophthalmitis: comparison of microbiology and molecular methods in the European Society of Cataract \& Refractive Surgeons multicenter study and susceptibility testing; the ESCRS Endophthalmitis Study Group. J Cataract Refract Surg 2008; 34:1439 1450

5. The Endophthalmitis Vitrectomy Study Group. Results of the endophthalmitis vitrectomy study; a randomized trial of immediate vitrectomy and of intravenous antibiotics for the treatment of postoperative bacterial endophthalmitis. Arch Ophthalmol 1995; $113: 14791496$

6. Lalwani GA, Flynn HW Jr, Scott IU, Quinn CM, Berrocal AM, Davis JL, Murray TG, Smiddy WE, Miller D. Acute-onset endophthalmitis after clear corneal cataract surgery (1996 2005); clinical features, causative organisms, and visual acuity outcomes. Ophthalmology 2008; 115:473 476
7. Wong TY, Chee S-P. The epidemiology of acute endophthalmitis after cataract surgery in an Asian population. Ophthalmology 2004; 111:699 705

8. Miller JJ, Scott IU, Flynn HW Jr, Smiddy WE, Corey RP, Miller D. Endophthalmitis caused by Streptococcus pneumoniae. Am J Ophthalmol 2004; 138:231 236

9. Soriano $F$, Pérez-Trallero E, Pallarés R, Meseguer MA, Fleites A, Gené A, González A, Liñares J, Esteban J, Baquero F, Valdés E, Muñoz-Almagro C. Streptococcus pneumoniae endophthalmitis: a study of 36 cases with special reference to antibiotic resistance and treatment options; on behalf of the Spanish Pneumococcal Infection Study Network. Clin Microbiol Infect 2006; 12:519 526

10. Mao LK, Flynn HW Jr, Miller D, Pflugfelder SC. Endophthalmitis caused by streptococcal species. Arch Ophthalmol 1992; 110:798 801

11. Miller JJ, Scott IU, Flynn HW Jr, Smiddy WE, Newton J, Miller D. Acute-onset endophthalmitis after cataract surgery (2000 2004): incidence, clinical settings, and visual acuity outcomes after treatment. Am J Ophthalmol 2005; 139:983 987

12. Pinna A, Zanetti S, Sotgiu M, Sechi LA, Fadda G, Carta F. Identification and antibiotic susceptibility of coagulase negative staphylococci isolated in corneal/external infections. $\mathrm{Br} \mathrm{J}$ Ophthalmol 1999; 83:771 773

13. Center KJ, Reboli AC, Hubler R, Rodgers GL, Long SS. Decreased vancomycin susceptibility of coagulase-negative staphylococci in a neonatal intensive care unit: evidence of spread of Staphylococcus warneri. J Clin Microbiol 2003; 41:4660 4665. Available at: http://jcm.asm.org/cgi/reprint/41/10/4660. Accessed April 18, 2009

14. Cimiotti JP, Haas JP, Della-Latta P, Wu F, Saiman L, Larson EL. Prevalence and clinical relevance of staphylococcus warneri in the neonatal intensive care unit. Infect Control Hosp Epidemiol 2007; 28:326 330

15. Shimamura $Y$, Kidokoro S, Murata M. Survey and properties of staphylococcus aureus isolated from Japanese-style desserts. Biosci Biotechnol Biochem 2006; 70:1571 1577. Available at: http://www.jstage.jst.go.jp/article/bbb/70/7/1571/ pdf. Accessed April 18, 2009

16. Aaberg TM Jr, Flynn HW Jr, Schiffman J, Newton J. Nosocomial acute-onset postoperative endophthalmitis; a 10-year review of incidence and outcomes. Ophthalmology 1998; 105:1004 1010

17. West ES, Behrens A, McDonnell PJ, Tielsch JM, Schein OD. The incidence of endophthalmitis after cataract surgery among the U.S. Medicare population increased between 1994 and 2001. Ophthalmology 2005; 112:1388 1394

18. Taban M, Behrens A, Newcomb RL, Nobe MY, Saedi G, Sweet PM, McDonnell PJ. Acute endophthalmitis following cataract surgery; a systematic review of the literature. Arch Ophthalmol 2005; 123:613 620

19. Jensen MK, Fiscella RG, Crandall AS, Moshirfar M, Mooney B, Wallin T, Olson RJ. A retrospective study of endophthalmitis rates comparing quinolone antibiotics. Am J Ophthalmol 2005; 139:141 148

20. Semmens JB, Li J, Morlet N, Ng J. Trends in cataract surgery and postoperative endophthalmitis in Western Australia (19801998): the Endophthalmitis Population Study of Western Australia. Clin Exp Ophthalmol 2003; 31:213 219

21. Lundström M, Wejde G, Stenevi U, Thorburn W, Montan P. Endophthalmitis after cataract surgery; a nationwide prospective study evaluating incidence in relation to incision type and location. Ophthalmology 2007; 114:866 870

22. Manners TD, Chitkara DK, Marsh PJ, Stoddart MG. Anterior chamber aspirate cultures in small incision cataract surgery. Br J Ophthalmol 1995; 79:878 880 
23. Beigi B, Westlake W, Mangelschots E, Chang B, Rich W, Riordan T. Peroperative microbial contamination of anterior chamber aspirates during extracapsular cataract extraction and phacoemulsification. Br J Ophthalmol 1997; 81:953 955

24. Dickey JB, Thompson KD, Jay WM. Anterior chamber aspirate cultures after uncomplicated cataract surgery. Am J Ophthalmol 1991; 112:278 282

25. Miller D, Flynn PM, Scott IU, Alfonso EC, Flynn HF Jr. In vitro fluoroquinolone resistance in staphylococcal endophthalmitis isolates. Arch Ophthalmol 2006; 124:479 483

26. Deramo VA, Lai JC, Fastenberg DM, Udell IJ. Acute endophthalmitis in eyes treated prophylactically with gatifloxacin and moxifloxacin. Am J Ophthalmol 2006; 142:721 725

27. Kernt M, Neubauer AS, Ulbig MW, Kampik A, WelgeLüßen U. In vitro safety of intravitreal moxifloxacin for endophthalmitis treatment. J Cataract Refract Surg 2008; 34: 480488

28. Montan PG, Wejde G, Setterquist H, Rylander M, Zetterström C. Prophylactic intracameral cefuroxime; evaluation of safety and kinetics in cataract surgery. J Cataract Refract Surg 2002; 28:982 987

29. Montan PG, Wejde G, Koranyi G, Rylander M. Prophylactic intracameral cefuroxime; efficacy in preventing endophthalmitis after cataract surgery. J Cataract Refract Surg 2002; 28:977 981

30. Gupta MS, McKee HD, Saldaña M, Stewart OG. Macular thickness after cataract surgery with intracameral cefuroxime. J Cataract Refract Surg 2005; 31:1163 1166 


\section{THE ESCRS ENDOPHTHALMITIS STUDY GROUP}

\section{Study Management Team}

Peter Barry (study chairman), Royal Victoria Eye and Ear Hospital, Dublin, Ireland; David Seal (study coordinator), Applied Vision Research Centre, City University, London, United Kingdom; George Gettinby, Magnus Peterson, ${ }^{*}$ Crawford Revie, Fiona Lees, Department of Computer and Information Sciences, Department of Statistics and Modelling Science, University of Strathclyde, Glasgow, Scotland (*currently at Atlantic Veterinary College, University of PEI, Canada)

\section{Pharmaceutical Advisers}

Klaus Geldsetzer (director marketing Europe), Santen GmbH, Germering, Germany; David Lloyd (industrial consultant), Surrey United Kingdom

\section{Clinical Partner Ophthalmologists}

Austria: Guenther Grabner, Stefan F. Egger, Josef Ruckhofer, University Eye Clinic, Paracelsus Private Medical University, Salzburg

Belgium: Johan Blanckaert, Jan Yperman Ziekenhuis, Campus Zwarte Zuster, Ieper; Camille Budo, Oogheelkunde, Melveren; Albert Galand, Jessica Crommen, Jean Rakic, Gaël Xhauflaire, Centre Hospitalier Universitaire, Liège; Marie-José Tassignon, UZA Ophthalmology, Edegem; Hugo Verbraeken, Rita de Donker, Universitair Ziekenhuis, Gent

Germany: Stefanie Schmickler, Augenklinik Ahaus, Ahaus

Italy: Roberto Bellucci, Simonetta Morselli, Sandro Soldati, Ospedale Borgo Trento, Verona; Fausto Vigasio, Marco Bertelli, Andrea Bottoli, Marta Cassamali, Fabrizio Danieli, Samer Khuri, Luigina Rosa, Azienda Ospedaliera di Desenzano del Garda, Desenzano del Garda

Poland: Jerzy Szaflik, Justyna Izdebska, Jacek P Szaflik, Department of Ophthalmology, Medical University of Warsaw, Warsaw

Portugal: Conceição Lobo, José Cunha-Vaz, Joaquin Mira, Department of Ophthalmology, University Hospital, Coimbra
Spain: Augusto Abreu, Jose Aguilar, Victor Arteaga, Luis Cordovés, Valentin T Díaz-Aleman, Manuel Gonzalez de la Rosa, Cristina Mantolan, Servicio de Oftalmologia, Hospital Universitario de Canarias, Tenerife; Pedro Abreu, Jorge Alvarez-Marin, Maria Antonia Gil, La Candelaria University Hospital, Tenerife; Jorge Alió, Instituto Oftalmologico VISSUM, Alicante; Miguel Teus, MT Alvarez, JM Román, Hospital Oftalmologico Internacional, Madrid

Turkey: Süleyman Kaynak, Osman Saatcý, Ýsmet Durak, Üzeyir Günenç, Tülin Berk, Meltem Söylev, Hakan Öner, Nilüfer Koçak, Mehmet Ergin, Dokuz Eylul University, Izmir

United Kingdom: David Allen, Peter Phelan, David Steel, Chris Wood, Sunderland Eye Infirmary, Sunderland; Carol Cunningham, Michael Miller, Ramesh Moorthy, Andleeb Zafar, Moorfields Eye Outreach Unit, Northwick Park Hospital, Harrow; Alex Ionides, Damian Lake, Graham Thompson, Moorfields Eye Outreach Unit, St. George's Hospital, London; John Jacob, Daniel Byles, Casper Gibbon, Andrew Kleinschmidt, Roland Ling, Anthony Quinn, Peter Simcock, George Sturrock, West of England Eye Unit, Royal Devon \& Exeter Hospital (Wonford), Exeter and Axminster Hospital, Axminster; William Kiel, Ipswich Hospital, Ipswich; Denise Mabey, David Spalton, Anupma Kumar, Department of Ophthalmology, St. Thomas' Hospital, London; Paul Rosen, CK Patel, John Salmon, Oxford Eye Hospital, Oxford, Exeter, and Axminster; Jean Dash, Linda Lindsell, Rebecca Turner, Oxford

\section{Data Monitoring Committee Members}

Stephen Barrett (Chairman), Charing Cross Hospital, London, England; Susanne Gardner, Atlanta, Georgia, USA; Susan Kennedy, National Ophthalmic Pathology Laboratory, Royal Victoria Eye and Ear Hospital, Dublin, Ireland; John Ludgate, London, England; Per Montan, St. Erik's Hospital, Stockholm, Sweden; Kirk Wilhelmus, Department of Ophthalmology, Cullen Eye Institute, Baylor College of Medicine, Houston, Texas, USA 